\title{
Endoscopic management of small bowel obstruction caused by intragastric balloon using antegrade single-balloon enteroscopy
}

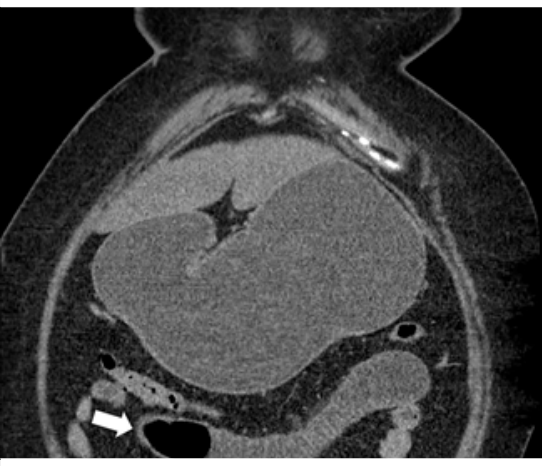

- Fig. 1 An abdominal computed tomography scan revealed a distally migrated intragastric balloon (white arrow) with evidence of luminal obstruction.

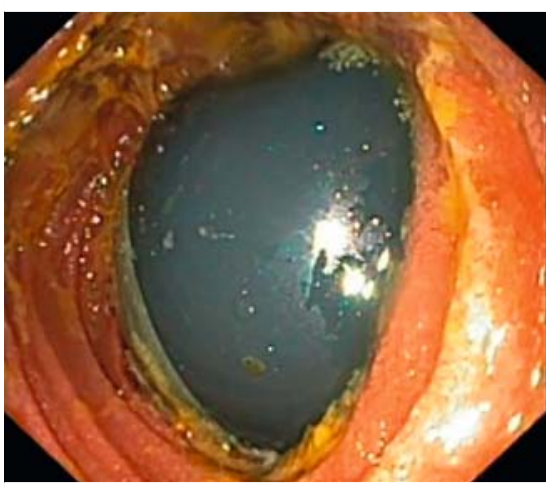

> Fig. 2 Migrated intragastric balloon at mid-jejunum totally occupied the lumen of the mid-jejunum.

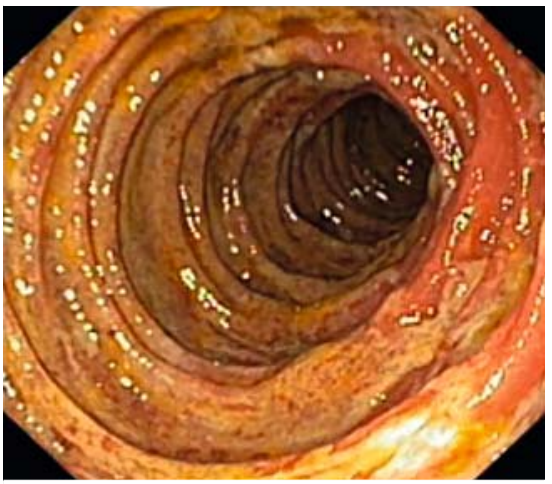

- Fig. 3 Proximal jejunum showed erythematous and edematous mucosa with circumferential ulceration.

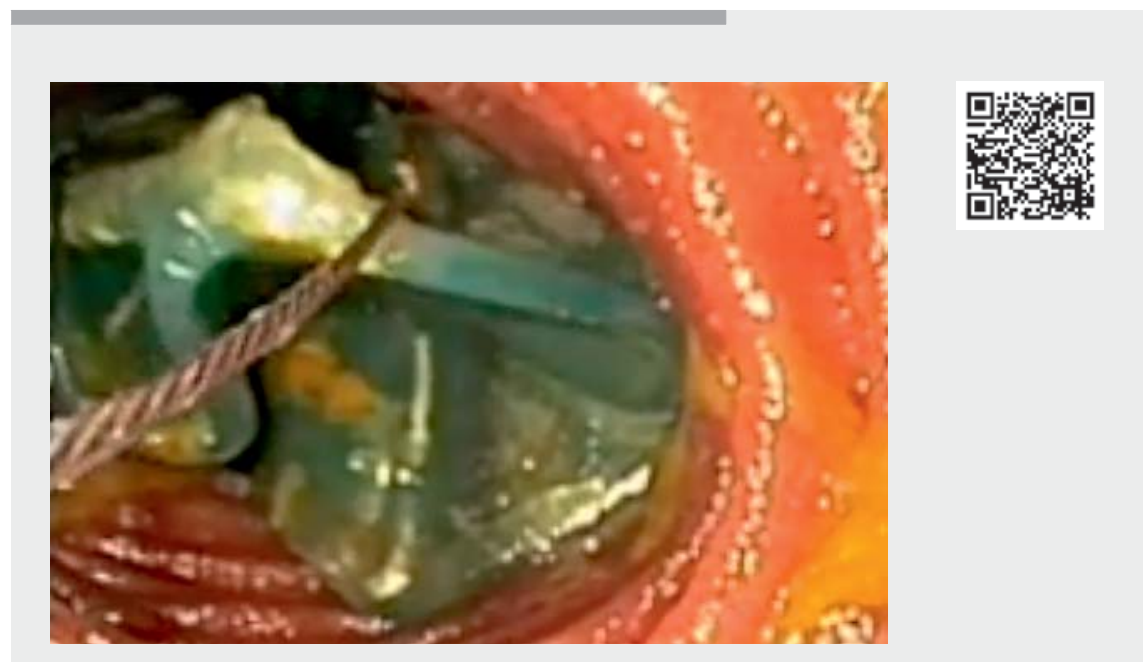

$\square$ Video 1 Removal of the migrated intragastric balloon using antegrade single balloonassisted enteroscopy.

A 44-year old woman with type 2 diabetes mellitus who underwent intragastric balloon (Spatz3) insertion 1 year ago presented with acute abdominal pain for 3 days. Abdominal examination showed mild tenderness at the epigastrium. Laboratory investigation showed a white blood cell count of $12,630 / \mathrm{mm}^{3}$. An abdominal computed tomography (CT) scan revealed a distally migrated intragastric balloon in the mid-jejunum causing a small bowel obstruction ( $\triangleright$ Fig. 1). After a discussion regarding treatment options, she decided to undergo endoscopic removal using antegrade single balloon-assisted enteroscopy.

On endoscopy, an intragastric balloon filled with methylene blue completely occupied the jejunal lumen ( $\mathbf{F i g . 2}$ ). Duodenal and proximal jejunal mucosa, especially the surrounding area, was markedly inflamed and covered with

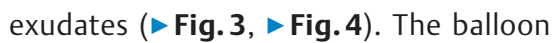
was punctured with a $25 \mathrm{G}$ needle, aspirated until completely collapsed, and then retrieved using a polypectomy snare ( Video 1, $>$ Fig. 5). A broad-spectrum intravenous antibiotic was given post- procedure. She was able to advance her diet and was safely discharged after hospitalization for 3 days.

Intragastric balloon insertion is a minimally invasive and effective procedure with favorable safety profiles. Migration of an intragastric balloon occurred in approximately one percent of cases whereas 0.3 percent had an intestinal obstruction [1]. The risk of spontaneous balloon deflation and possible subsequent migration increases over time, especially after 6 months [2]. An intragastric balloon causing obstruction in the proximal duodenum is likely to be successfully removed endoscopically, whereas more distal migrations have been successfully treated laparoscopically, with few reports of percutaneous aspiration [2,3]. At present, only two cases of successful endoscopic treatment of a migrated intragastric balloon using double balloon-assisted enteroscopy have been reported $[4,5]$. We reported the first experience using antegrade singleballoon enteroscopy to a remove a migrated intragastric balloon. Meticulous care should be taken while gently with- 


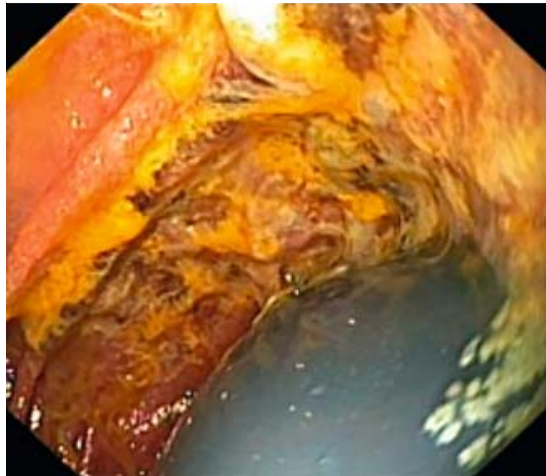

- Fig. 4 Endoscopic image of surrounding jejunal mucosa showed erythematous, edematous changes, and ulceration with overlying yellowish sludge.

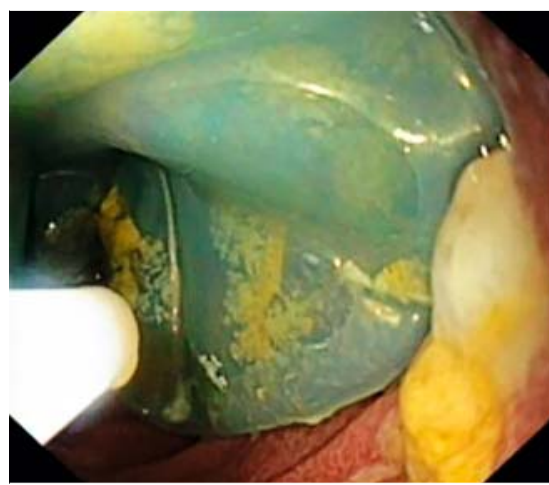

- Fig. 5 The balloon was firmly grasped with a polypectomy snare before gentle removal.

drawing the scope with the attached balloon tightly grasped. Trauma to surrounding inflamed mucosa should be kept to a minimum.

Endoscopy_UCTN_Code_CPL_1AH_2A J

\section{Competing interests}

The authors declare that they have no conflict of interest.

\section{Manus Rugivarodom ${ }^{1}$, Theera}

Pongprasopchai ${ }^{2}$, Chompol Yamcharoen ${ }^{3}$, Kotchakon Maipang ${ }^{1}$, Varayu Prachayakul ${ }^{1}$

1 Siriraj GI Endoscopy Center, Division of Gastroenterology, Department of Internal Medicine, Faculty of Medicine, Siriraj hospital, Mahidol University, Bangkok, Thailand

2 Surgery Unit, Thonburi Hospital, Bangkok, Thailand

3 Liver and Digestive Institute, Thonburi Hospital, Bangkok, Thailand

\section{Corresponding author}

\author{
Varayu Prachayakul, MD \\ Siriraj GI Endoscopy Center, Division of \\ Gastroenterology, Department of Internal \\ Medicine, Faculty of Medicine, Siriraj \\ Hospital, Mahidol University, Bangkok \\ 10700, Thailand \\ Fax: +66-2-411-5013 \\ kaiyjr@gmail.com
}

\section{References}

[1] Abu Dayyeh BK, Kumar N, Edmundowicz SA et al. ASGE Bariatric Endoscopy Task Force systematic review and meta-analysis assessing the ASGE PIVI thresholds for adopting endoscopic bariatric therapies. Gastrointest Endosc 2015; 82: 425-438

[2] Hay D, Ryan G, Somasundaram M et al. Laparoscopic management of a migrated intragastric balloon causing mechanical small bowel obstruction: a case report and review of the literature. Ann R Coll Surg Engl 2019; 101: e172-e177

[3] Brooks J, Rimon U, BenSaid P et al. Percutaneous needle aspiration of a partially deflated intragastric balloon: a forgotten modality? Review of the literature Obes Surg 2018; 28: 1781-1784

[4] Halm U, Grothoff M, Lamberts R. Gastric balloon causing small bowel obstruction: treatment by double-balloon enteroscopy. Endoscopy 2013; 45: E78-E79

[5] Vlachou E, Direkz S, Murino A et al. Small bowel obstruction caused by a migrated Obalon gastric bariatric balloon: nonsurgical management by antegrade double-balloon panenteroscopy. Endoscopy 2016; 48: E403-E404
Bibliography

Endoscopy 2022; 54: E624-E625

DOI 10.1055/a-1724-7016

ISSN 0013-726X

published online 26.1.2022

(C) 2022. Thieme. All rights reserved.

Georg Thieme Verlag KG, Rüdigerstraße 14 , 70469 Stuttgart, Germany

\section{ENDOSCOPY E-VIDEOS}

https://eref.thieme.de/e-videos

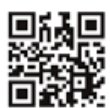

Endoscopy E-Videos is an open access online section, reporting on interesting cases and new techniques in gastroenterological endoscopy. All papers include a high quality video and all contributions are freely accessible online. Processing charges apply (currently EUR 375), discounts and wavers acc. to HINARI are available.

This section has its own submission website at https://mc.manuscriptcentral.com/e-videos 